\title{
Editorial
}

\section{La rédaction}

\section{(2) OpenEdition}

Journals

Édition électronique

URL : http://journals.openedition.org/ethnoecologie/6367

DOI : $10.4000 /$ ethnoecologie. 6367

ISSN : 2267-2419

\section{Éditeur}

Laboratoire Eco-anthropologie et Ethnobiologie

\section{Référence électronique}

La rédaction, «Editorial », Revue d'ethnoécologie [En ligne], 18 | 2020, mis en ligne le 31 décembre 2020 consulté le 29 janvier 2021. URL : http://journals.openedition.org/ethnoecologie/6367 ; DOI : https:// doi.org/10.4000/ethnoecologie.6367

Ce document a été généré automatiquement le 29 janvier 2021.

\section{(c) (i) (9)}

Revue d'ethnoécologie est mis à disposition selon les termes de la licence Creative Commons Attribution - Pas d'Utilisation Commerciale - Pas de Modification 4.0 International. 


\section{Editorial}

\section{La rédaction}

1 À l'été 2018, Françoise Aubaile-Sallenave a pris l'initiative de réunir en hommage à Serge Bahuchet, des textes de chercheurs ayant tous travaillé de près ou de loin avec lui, dans l'optique interdisciplinaire. C'est cette approche, telle qu'elle est définie sur le site de la Revue à cette page : https://journals.openedition.org/ethnoecologie/1593, qui était également celle du LACITO (Laboratoire de langues et civilisations à tradition orale UMR 7107) où Serge Bahuchet a été chercheur de 1979 à 1999, et aussi celle de l'UMR 7206 "éco-anthropologie \& ethnobiologie » du Muséum national d'histoire naturelle qu'il a fondée en 2000 et dirigée jusqu'à 2018 , ce qui a motivé la réunion de ces articles d'hommage.

2 L'idée de Françoise Aubaile a d'abord été de publier ces Mélanges dans la Revue d'Ethnoécologie. Le liber amicorum devait lui être offert, comme une surprise, lors d'une fête qui a réuni autour de lui une bonne centaine de ses amis, au Musée de l'Homme le 16 septembre 2019, et qui marquait ses cinquante années d'engagement dans la recherche ethnoécologique!

3 Ces articles comportaient, à des degrés divers, des références personnelles et des marques de complicité, de gratitude, d'amitié voire d'affection, inhabituelles dans une revue scientifique, de celles qu'on ne commence à prodiguer en général que lors d'un départ en retraite ou d'un enterrement, et donc fort heureusement complètement prématurées en l'espèce.

4 En accord avec la directrice de l'UMR 7206, Evelyne Heyer, il a été convenu d'une part de laisser toute son originalité au recueil de textes d'hommage édité par Françoise Aubaile, qui sera publié in extenso très bientôt, et d'autre part, de reprendre dans un ou plusieurs numéros de la Revue d'Ethnoécologie ceux de ces articles qui s'inscrivent le mieux dans la perspective pluridisciplinaire de la Revue. C'est ce que nous commençons à faire dans ce numéro 18 avec les articles de Françoise et Pierre Grenand, de Régis Ollomo Ella, de Catherine Sabinot, de Claudie Haxaire, de Philippe Mennecier et de Françoise Aubaile

5 Il aurait été extrêmement dommage, en effet, que ces articles de grande valeur ne finissent par être confinés, ou publiés dans d'autres revues, alors qu'ils apportent une 
matière superbe à notre Revue et s'inscrivent à merveille dans le droit fil de nos traditions et de nos ambitions telles que rappelées plus haut, avec ces quatre mots clés : originalité, ethnoécologie, interdisciplinarité, terrain. 